\title{
Kingella kingae causing septic arthritis in Felty's syndrome
}

\author{
D. A. LEWIS \\ M.B., M.R.C.Path. \\ L. SETTAS \\ M.D.
}

Departments of Microbiology and Rheumatology, Bristol Royal Infirmary, Bristol BS2 8HW

\begin{abstract}
Summary
A case of septic arthritis of the elbow caused by Kingella kingae, a Gram-negative bacillus, is described. The patient had long-standing, severe rheumatoid arthritis and Felty's syndrome. This appears to be the first report from the United Kingdom of Kingella kingae as the aetiological agent of septic arthritis.
\end{abstract}

KEY WORDS: Kingella kingae, septic arthritis, Felty's syndrome.

\section{Introduction}

Kingella kingae was the first species to be named in the genus Kingella, defined in 1976 (Henriksen and Bøvre, 1976). It shares many characteristics with the genus Moraxella and was indeed previously named Moraxella kingii (Henriksen and Bøvre, 1968). The pathogenic significance of this bacterium in bone and joint infections has been reported recently from North America and Australia (Redfield et al., 1980; Vincent et al., 1981; Davis and Peel, 1982). We report a case of septic arthritis due to Kingella kingae in a patient with Felty's syndrome.

\section{Case report}

A 51-year-old woman with a 16-year history of seropositive, erosive rheumatoid arthritis was admitted with a history of pain and swelling of the right elbow over a period of 3 days. Previous therapy for her arthritis had included various non-steroidal antiinflammatory drugs and courses of gold and Dpenicillamine. She had had bilateral hip replacements and a synovectomy of the left wrist. At the time of admission, she was taking non-steroidal, antiinflammatory drugs only. Six months before this admission, she had suffered an episode of septic arthritis of the right knee due to Staphylococcus aureus, which had responded satisfactorily to a 3month course of flucloxacillin and sodium fusidate.

On examination, she was in pain but was apyrexial. The right elbow was tender and swollen with a large, tense effusion. Fifteen millilitres of pus were aspirated from over the radial head and intravenous ampicillin and flucloxacillin, both $500 \mathrm{mg}$ 6-hourly, were commenced immediately. Direct culture of the pus, both aerobically and anaerobically, yielded no bacterial growth, but enrichment culture (ToddHewitt broth), after 2 days, yielded, on subculture to $5 \%$ horse blood agar, a pure growth of a Gramnegative coccobacillus. This was very sensitive to many antibiotics, including benzylpenicillin, tetracycline and erythromycin. The bacterium produced two colony-types on solid medium, one pin-point, and the other larger, corroding the agar. Both types had zones of clear beta-like haemolysis. The organism was subjected to biochemical tests, of which the following important reactions confirmed its identity as Kingella kingae: a positive oxidase and negative catalase reaction, the fermentation of glucose and maltose but not mannitol, lactose or sucrose, and the absence of urease and indole production (Weaver and Hollis, 1980).

Regular aspiration of the elbow was performed but no further specimens yielded any bacterial growth. After 3 days of intravenous antibiotics, therapy was changed to oral ampicillin, $500 \mathrm{mg}$ 6-hourly, and the elbow gradually improved. Further investigations revealed a neutropaenia (total white blood cells $2.9 \times 10^{9} /$ litre $51 \%$, neutrophils), and mild splenomegaly, compatible with a diagnosis of Felty's syndrome.

\section{Discussion}

Felty's syndrome is characterized by splenomegaly and leucopaenia superimposed upon severe, usually long-standing rheumatoid arthritis. While rheumatoid arthritis itself is common, Felty's syndrome affects only $1 \%$ of patients seeking hospital advice for rheumatoid arthritis (Moore et al., 1971). Chronic, recurrent, often severe bacterial infections of various sorts are seen in patients with Felty's syndrome and, indeed, this patient had suffered a previous episode of septic arthritis. The causative agent on that occasion was Staphylococcus aureus, the bacterium 
most commonly isolated from septic joints in rheumatoid arthritis (Newman, 1976). Conversely, Kingella kingae, the bacterium isolated from joint fluid on the second occasion, has only rarely been reported as a pathogen in bone and joint infections. None of the previously reported cases have been patients with pre-existing pathological joints. The only other adult to be described was a bartender with a history of alcohol abuse (Vincent et al., 1981). All other cases have been children, one of these a 4-year-old boy with acute lymphoblastic leukaemia, who had skin lesions and a warm swollen and tender left knee. In this patient, Kingella kingae was isolated from blood culture (Redfield et al., 1980). Davis and Peel (1982) reported 3 other cases, all children: a 6-month-old boy with osteomyelitis of the manubriosternum, a 2year-old boy with chronic osteomyelitis of the left femur and a 13-year-old boy with septic arthritis of the left hip. All the cases so far reported have been treated successfully with antibiotics, given either as single agents or in combination. There is no defined optimum antibiotic therapy for Kingella kingae infection but it is very sensitive to a number of agents. Given the wide choice, it would seem desirable to select one (such as a penicillin) with a high therapeutic index. There is no evidence that the duration of therapy should differ from that of any other acute infection of bone or joint.

The natural habitat of Kingella kingae is probably the mucous membrane of the upper respiratory tract (Henriksen, 1969), and it is assumed that spread to joints is by the haematogenous route. Of 75 isolates referred to the Centre for Disease Control, Atlanta, 21 have come from bone- or joint-associated sites (Weaver and Hollis, 1980); no further clinical details accompanied this report. It has been suggested that Kingella kingae can be mistaken easily for a $\beta$ haemolytic streptococcus, and this we should endorse, since our isolate tended to resist decolorization on Gram-staining, was often coccal in form and produced $\beta$-haemolysis on horse-blood agar.
Kingella kingae is not a commonly encounterêd organism in bone and joint infections but the should be general awareness of its pathogenic roleqn these infections. The case reported here illustrates also the value of enrichment culture of joint fluid $\overrightarrow{\vec{s}}$ cases of septic arthritis, since without it Kingehla kingae would not have been isolated from this patient.

\section{Acknowledgments}

We wish to thank Dr P. Dieppe for advice and permissioño report this case, and Professor D. C. E. Speller for helpful criticistn.

\section{References}

Davis, J.M. \& PeEL, M.M. (1982) Osteomyelitis and septic arthæु. caused by Kingella kingae. Journal of Clinical Pathology, 35, 2t t . HENRIKSEN, S.D. (1969) Corroding bacteria from the respiratory tract. 1. Moraxella kingii. Acta Pathologica et Microbiologisa Scandinavia, 75, 85.

HENRIKSEN, S.D. \& BøVRE, K. (1968) Moraxella kingii sp. no haemolytic, saccharolytic species of the genus Moraxella. Joutmal of General Microbiology, 51, 377.

HENRIKSEN, S.D. \& BøVRE, K. (1976) Transfer of Moraxella kingae Henriksen and Bøvre to the genus Kingella gen. nov. in the family Neisseriacae. International Journal of Systemic Bacteriology, $\frac{126}{26}$, 447.

MOORE, R.A., BRUNNer, C.M., SANDUSKy, W.R. \& LEAVELl, Hes. (1971) Felty's syndrome; long-term follow-up after splenectomy. Annals of Internal Medicine, 75, 381.

NEWMAN, J.H. (1976) Review of septic arthritis throughoint antibiotic era. Annals of Rheumatic Diseases, 35, 198.

ReDFIeld, D.C., OverTURF, G.D., EwING, N.\& Powars, D. 8980$)$ Bacteria, arthritis and skin lesions due to Kingella kingae. Arch heses of Disease in Childhood, 55, 411.

Vincent, J., PodeWell, C., Franklin, G.W. \& KorN, J.H. (1981) Septic arthritis due to Kingella (Moraxella) kingii: case report review of the literature. Journal of Rheumatology, 8, 501.

WEAVER, R.E. \& HolLIS, D.G. (1980) Gram-negative fermentate bacteria and Francisella tularensis. In: LENNETTE, E.H., BALO A., Hansler, W.J., Truant, J.P. eds. (1980). Manual of Clinical Microbiology (Eds. E.H. Lennette, A. Balows, W.J. Hansler 蛋d J.P. Truant) 3rd edn., p. 253. American Society for Microbiolögy, Washington, D.C.

(Accepted 25 November 1982) 